\title{
Indices of Canada's future climate for general and agricultural adaptation applications
}

\author{
Guilong $\mathrm{Li}^{1} \cdot$ Xuebin $\mathrm{Zhang}^{1}$ (D) - Alex J. Cannon ${ }^{1}$ • \\ Trevor Murdock ${ }^{2} \cdot$ Steven Sobie $^{2} \cdot$ Francis Zwiers $^{2}$. \\ Kevin Anderson ${ }^{1} \cdot$ Budong Qian $^{3}$
}

Received: 3 October 2016 / Accepted: 1 April 2018 / Published online: 25 April 2018

(C) The Author(s) 2018

\begin{abstract}
This study evaluates regional-scale projections of climate indices that are relevant to climate change impacts in Canada. We consider indices of relevance to different sectors including those that describe heat conditions for different crop types, temperature threshold exceedances relevant for human beings and ecological ecosystems such as the number of days temperatures are above certain thresholds, utility relevant indices that indicate levels of energy demand for cooling or heating, and indices that represent precipitation conditions. Results are based on an ensemble of high-resolution statistically downscaled climate change projections from 24 global climate models (GCMs) under the RCP2.6, RCP4.5, and RCP8.5 emissions scenarios. The statistical downscaling approach includes a bias-correction procedure, resulting in more realistic indices than those computed from the original GCM data. We find that the level of projected changes in the indices scales well with the projected increase in the global mean temperature and is insensitive to the emission scenarios. At the global warming level about $2.1{ }^{\circ} \mathrm{C}$ above pre-industrial (corresponding to the multi-model ensemble mean for 20312050 under the RCP8.5 scenario), there is almost complete model agreement on the sign of projected changes in temperature indices for every region in Canada. This includes projected increases in extreme high temperatures and cooling demand, growing season length, and decrease in heating demand. Models project much larger changes in temperature indices at the higher $4.5^{\circ} \mathrm{C}$ global warming level (corresponding to 2081-2100 under the RCP8.5 scenario). Models also project an increase in total precipitation, in the frequency and intensity
\end{abstract}

Electronic supplementary material The online version of this article (https://doi.org/10.1007/s10584-0182199-x) contains supplementary material, which is available to authorized users.

\section{Xuebin Zhang}

Xuebin.Zhang@Canada.ca

Climate Research Division, Environment and Climate Change Canada, Toronto, Ontario, Canada

2 Pacific Climate Impacts Consortium, University of Victoria, Victoria, BC, Canada

3 Agriculture and Agri-Food Canada, Ottawa Research and Development Centre, Ottawa, Ontario, Canada 
of precipitation, and in extreme precipitation. Uncertainty is high in precipitation projections, with the result that models do not fully agree on the sign of changes in most regions even at the $4.5^{\circ} \mathrm{C}$ global warming level.

\section{Introduction}

Changes in Canada's climate have widespread impacts on the environment, economic activity, and human health, especially in the north where warming is proceeding more rapidly and where ecosystems and traditional lifestyles are particularly sensitive to the impacts of warming (Allard and Lemay 2012; Warren and Lemmen 2014). For example, thawing permafrost in Canada's North has had detrimental effects on infrastructure such as highways and buildings (Prowse et al. 2009; Stephani et al. 2014). In southern Canada, temperature increase has also resulted in a significant challenge for the energy sector to meet peak electricity load in summer due to an increasing cooling demand (Wilbanks et al. 2008; OSPE 2012). Changes to the growing season have also occurred, including prolonged growing seasons for warm season crops and more crop heat units (accumulated amount of heat within a growing season) in general (Qian et al. 2012). Further change seems inevitable given that warming, and its amplification at high northern latitudes, is likely to continue under all emission scenarios. This may enable northward expansion of some crops (Beaubien and Hamann 2011), although not all crops will benefit from a longer growing season due to other factors - soil and water conditions, plant physiology, etc.- - that may limit the climate envelopes within which crops perform well (e.g., Lobell and Gourdji, 2012).

Adaptation planning requires scientifically sound information about the future climate. Global climate models (GCMs) simulate future climate under different emission scenarios. However, GCMs simulate average conditions over large grid cells - typically about $10,000 \mathrm{~km}^{2}$ or more per cell — which is often too coarse a resolution for regional and local applications. Bias in simulated local climate is also of concern for many applications. The median temperature simulated by the GCMs participating in the Coupled Model Intercomparison Project Phase 5 (CMIP5) has biases ranging from -3 to $1.5^{\circ} \mathrm{C}$ for seasonal and annual mean temperatures in 26 global land areas relative to the Climate Research Unit highresolution gridded dataset (CRU TS3.10, Flato et al. 2013). Precipitation simulated by CMIP5 models also has considerable bias compared to observations (Flato et al. 2013). These biases hinder the direct application of simulated future climate for impacts modeling and adaptation planning, since climate impacts are often associated with fixed physical or biophysical thresholds. For example, temperatures exceeding $29.5^{\circ} \mathrm{C}$ can result in heat stress to canola and consequently reduced yields (Qian et al. 2018). As a result, adaptation planning often uses simulated future climate information that has incorporated some form of downscaling and bias correction. These methods allow blending information from historical observations with climate change projections from climate models. While downscaling and bias correction methods can be useful and fit for some purposes, it is important to assess critically whether model biases can be meaningfully corrected (Maraun 2016). Naive application of downscaling and bias correction can result in ill-informed adaption decisions (Maraun et al. 2017). In the end, climate information is more useable and less prone to misinterpretation when presented in a manner specific to the impacts of concern to the local community. High-resolution future projections of impact-relevant climate indices can be particularly useful in this regard. 
In North America, bias corrected, downscaled climate scenarios are available for the USA (e.g., Maurer et al. 2007) and have been used to produce impact-relevant projections of climate indices. Ficklin et al. (2016) calculated aridity and drought indices for the contiguous USA from downscaled daily GCM projections. They identified bias correction and downscaling as being necessary to make credible projections of these indices. The current study is the first such work at these spatial and temporal resolutions for Canada. Here, we describe and present future projections for a suite of impact-relevant climate indices tailored for Canadian users from different sectors. The indices are computed based on bias corrected, downscaled GCMs for current and future climates. In the remainder of this paper, we describe the indices and climate data in Section 2, provide results in Section 3, and present a summary and conclusions in Section 4.

\section{Climate indices and data}

\subsection{Climate indices}

Many existing climate indices such as the ETCCDI (joint CCl-CLIVAR-JCOMM Expert Team on Climate Change Detection and Indices) indices (Zhang et al. 2011) were developed for understanding the past and future changes in climate extremes (e.g., Sillmann et al. 2013a, b). They are not, however, always relevant for tracking climate impacts at the regional and local scales. To address the needs of different user groups in Canada, we consider agroclimate indices specific to the three main crop types grown in Canada (Qian et al. 2013) and other indices proposed by the Canadian adaptation community through a series of consultations. Table S1 provides definitions of these indices. The indices fall into four general categories. One group describes the state of the climate including annual and monthly mean temperatures and total precipitation. Another group considers the counts of the number of days when temperature or precipitation exceeds (or is below) a threshold value, such as annual counts of days with maximum temperature greater than $30^{\circ} \mathrm{C}$. A third group describes the lengths of episodes when a particular weather/climate condition occurs, for example, hot spell or dry spell length. The fourth group consists of indices that accumulate temperature departures above or below a fixed threshold. These include heating, cooling or growing degree-days, and crop heat units.

\subsection{Data and methods}

We use spatially interpolated $\sim 10 \mathrm{~km}$ resolution $\left(1 / 12^{\text {th }}\right.$ degree $)$ daily maximum and minimum temperatures and total precipitation for the period 1950-2010 as "observational" data (McKenney et al. 2011). This data set is based on daily observations from across Canada and a thin-plate smoothing splines interpolation scheme. While the gridded precipitation and temperature data have been evaluated with station observations, the impact of gridding on the indices used in this study has not been previously evaluated. We will therefore compare indices computed from this gridded dataset with those computed from station observations at 10 locations representing different Canadian climates (see Fig. 1 and Section 3.1 for results). Figure S1 shows a map of Canada along with the geographical names, regional boundaries, and locations of these stations. Table S2 lists additional details about the stations. 

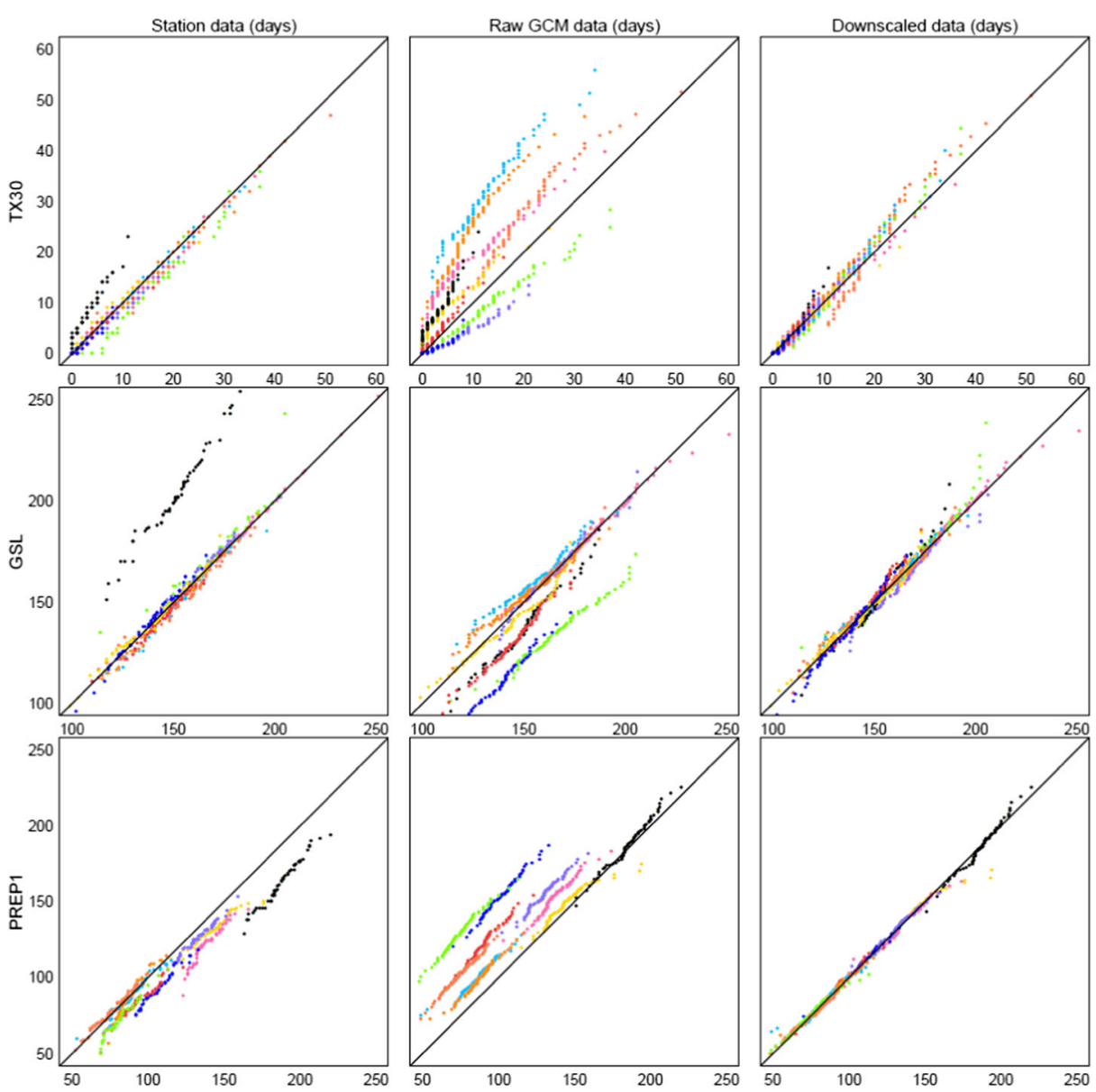

Fig. 1 Q-Q plots for the number of hot days with daily maximum temperature greater than $30{ }^{\circ} \mathrm{C}$ (TX30, upper panel), for the length of growing season for warm seasons crops (GSL, middle panel), and for number of days with precipitation amount greater than $1 \mathrm{~mm}$ (Prep1, lower panel) and at the 10 stations (different colors) listed in Table S2 for 1950-2010. The plots compare the quantiles of the gridded observational data (horizontal axis) with the quantiles of station observations (vertical axis, left column), raw GCM output (vertical axis, central column), and downscaled GCM output (vertical axis, right column)

The IPCC Fifth Assessment Report (AR5) produced the Atlas of Global and Regional Climate Projections (Annex 1, IPCC 2013) to provide a synthesis of results from the CMIP5 multi-model ensemble. The atlas uses monthly values of precipitation and surface mean temperatures simulated by 29 GCMs, which have spatial resolutions ranging from about $1^{\circ} \times 1^{\circ}$ to over $2.5^{\circ} \times 2.5^{\circ}$ (latitude $\times$ longitude). We downscale daily temperatures and precipitation amounts simulated by 24 of these GCMs (all models for which daily values were available at the time of analysis; see Table S3) to $\sim 10 \mathrm{~km}$ resolution over Canada using the BCCAQ method described by Murdock et al. (2014) and Werner and Cannon (2016). We considered the RCP2.6, the RCP4.5, and the RCP8.5 emission scenarios (van Vuuren et al. 2011) for the future projections.

Various statistical downscaling methods, including versions of bias-correction/constructed analogues (BCCA, Maurer et al. 2010), quantile mapping (Gudmundsson et al. 2012), and 
bias-correction/spatial disaggregation (BCSD; Wood et al. 2004) were evaluated as a followup to the downscaling intercomparison by Bürger et al. (2012, 2013). A method called BCCAQ, which combines downscaling by BCCA with bias correction by trend-preserving quantile mapping (Cannon et al., 2015), was found to produce the most robust projections according to a set of tests that measure day-to-day temporal sequencing, equality of distributions, and spatial co-variability (Murdock et al. 2014; Werner and Cannon 2016). Evaluation was performed via temporal split-sample validation with multiple reanalyses standing in for GCMs (Werner and Cannon 2016), as well as a "perfect model" setup (Dixon et al. 2016) in which spatially degraded RCM projections stand in for GCMs to test robustness under future climate conditions (Murdock et al. 2014).

Ideally, the marginal distributions and spatiotemporal variability of statistically downscaled data should be comparable to that of observation-based gridded data. In practice, Maraun (2013) and Guttmann et al. (2014) demonstrated that certain types of downscaling/bias correction - those that operate on individual high-resolution grid boxes separately and independently - are prone to "variance inflation" or misrepresentation of spatially aggregated extremes. BCCAQ avoids these issues by separating the downscaling and bias correction operations: BCCA, which includes a quantile mapping step at the GCM scale and subsequently generates realistic fine-scale spatial variability, precedes the application of second quantile mapping at each grid point to further correct quantile distributions at the fine scale. Furthermore, the quantile mapping algorithm that is used explicitly preserves the climate change signal—additively for temperature and multiplicatively for precipitation —of the underlying climate model projections (Cannon et al. 2015).

We use the downscaled data generated by BCCAQ in this study. BCCAQ was calibrated using a 1950-2010 historical reference period and was applied to daily maximum temperature, daily minimum temperature, and precipitation projections separately. Downscaling different variables independently can lead to small numbers of cases of physical inconsistency (i.e., minimum temperatures that occasionally exceed maximum temperatures; Thrasher et al. 2012). Tests indicate minimal impact on the indices of interest for BCCAQ downscaled data. For instance, while cold season indices were affected most strongly, ad hoc "correction" of inconsistent temperatures does not have appreciable impacts on projected changes. For example, swapping inconsistent minimum/ maximum temperatures leads to negligible differences in end-of-century projected changes in winter mean temperature (a maximum reduction in projected changes over all grid cells for CanESM2 RCP8.5 of less than $\left.0.3^{\circ} \mathrm{C}\right)$ and the number of days with minimum temperature less than $-15^{\circ} \mathrm{C}( \pm$ 1 day). Hence, all reported results are based on the original, independently downscaled data. Code implementing the method is available from https://cran.r-project.org/package=ClimDown. Daily downscaled climate projections for Canada using BCCAQ will become available from the Pacific Climate Impacts Consortium (https://www.pacificclimate.org/data/) and Environment and Climate Change Canada's Canadian Climate Data and Scenarios website (http://climate-scenarios.canada.ca).

\section{Results}

\subsection{Evaluation of the gridded data and simulated products}

As an illustration, the left panel of Fig. 1 shows quantile-quantile (Q-Q) plots between grid and station observations at the 10 observing stations for three indices, the number of days with 
daily maximum temperature greater than $30^{\circ} \mathrm{C}$ (TX30), the length of growing season (GSL) for warm season crops, and the number of days with precipitation amount greater than $1 \mathrm{~mm}$ (Prep1). Indices computed from the gridded observational data compare well with those computed from station data. There are no apparent systematic differences for most indices (not shown). The difference in the elevations of the grid box and the station at Agassiz (black dots) explains the differences in temperature indices, while the effect of smoothing by the gridding procedure can explain the slightly larger number of precipitation days from the gridded data.

To compare multiple model simulations with observations at a particular location for 19502010, we first estimate quantiles in the simulated data for individual models separately and then compute the ensemble average of the quantiles from the 24 GCMs. The central panels of Fig. 1 displays Q-Q plots that compare model ensemble average quantiles with quantiles from gridded observations for the three indices. There are systematic biases in indices directly computed from the GCM simulations. The temperature indices have different biases in both magnitude and direction at different locations. Compared with gridded observations, the models simulate too many precipitation days at all locations. Various biases also exist for other indices (not shown). This indicates the need to bias-correct the model data in order to compute indices properly.

The right panels of Fig. 1 shows Q-Q plots that compare ensemble-averaged quantiles from the downscaled datasets with those from the gridded observations. As expected, biases seen in the raw GCM simulations essentially disappear in the downscaled data. Biases are also minimal for the other indices, indicating that the downscaling procedure has corrected model biases as intended. As the downscaling procedure is not trained against the indices from the gridded data, correction of bias for these indices does provide confidence in the usefulness of the procedure. This is consistent with the findings of Cannon et al. (2015) and Ficklin et al. (2016) and satisfies a key requirement for the data to be suitable in projecting changes in climate indices at regional and local scales. Comparison with homogenized data at 80 observing stations (Vincent et al. 2012; Mekis and Vincent 2011) provides essentially the same results (not shown).

\subsection{Projected changes in indices}

Seneviratne et al. (2016) showed that changes in extreme temperature and precipitation over large regions scale with global temperature increase across emission scenarios. Linking regional or national impacts to specified global warming levels provide a convenient way to communicate climate change information to adaptation community. Figure 2 shows the projected changes in Canadian mean temperature plotted against global warming levels. The global warming level is defined in terms of the 20 -year running average of multi-model ensemble mean of global temperature relative to its pre-industrial (1861-1900) level. It is clear that long-term changes in Canada's mean temperature scale with corresponding changes in global mean temperature across the three emission scenarios and at the rate about twice of global mean temperature. Changes in regional averages of indices in turn scale well with changes in Canada's mean temperature across emission scenarios. As an illustration, we plotted in the right panel of Fig. 2 changes in the length of the growing season in the Canadian Prairies (including Alberta, Saskatchewan, and Manitoba) as a function of Canadian mean temperature change. This is also the case for other indices as well, as can be seen by comparing projected changes at a global warming level of $2{ }^{\circ} \mathrm{C}$ under RCP4.5 and RCP8.5 (see 

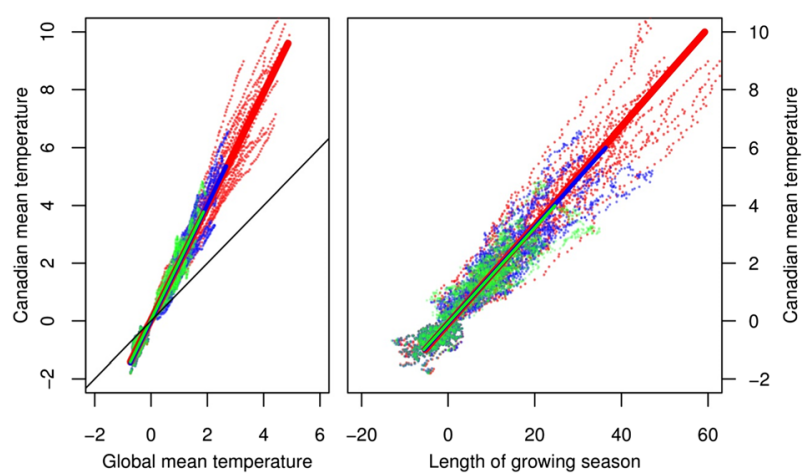

Fig. 2 Projected changes in Canadian mean temperature as a function of changes in global mean temperature (left panel), and the projected changes in the length of growing season for warm season crops in the Prairies (right panel) as a function of changes in Canadian mean temperature (the abscissa is on the vertical axis) under different emission scenarios. Projected changes in Canadian temperature and in length of growing season are represented by 20-year running averages relative to their respective 1986-2005 averages while projected changes in global mean temperature expressed relative to its pre-industrial level. The dots show results from individual models while lines are least-square fits for three RCP scenarios. The green, blue, and red colors correspond to results for the RCP2.6, RCP4.5, and RCP.8.5 scenarios. The black line on the left panel indicates the 1:1 slope for reference

Supplementary Figs. S2, S3, S4). We therefore present projected changes for the near term (2031-2050) and for the end of the twenty-first century (2081-2100) under the RCP8.5 scenario. In all cases, project changes in indices are taken with respect to a 1986-2005 baseline period. The corresponding global mean temperatures projected by the $24 \mathrm{GCMs}$ are 2.1 and $4.5^{\circ} \mathrm{C}$ above the pre-industrial level, respectively; which will be referred to as the 2.1 and $4.5^{\circ} \mathrm{C}$ warming levels in the remainder of the paper.

To facilitate the discussion, we show projected ensemble median changes due to anthropogenic influence for selected indices as maps. In addition, we provide the median, the 5th, and the 95th percentiles from the ensemble for large regions in Tables S4 and S5. The spatial regions include British Columbia (BC), the Canadian Prairies (Prairie), Ontario (ON), Quebec (QC), the Atlantic Provinces (ATL; including New Brunswick, Nova Scotia, Newfoundland and Labrador, and Prince Edward Island), and the northern territories (NN; including Yukon, Northwest Territories, and Nunavut).

\subsubsection{Temperature-related indices}

Figure 3 displays projected changes in the number of days with daily maximum temperature above $30^{\circ} \mathrm{C}$ (TX30; "hot days") and the number of days with daily minimum temperature below $-15^{\circ} \mathrm{C}$ (TNm15; "cold nights"). Consistent with projected warming, models project an increase in the number of hot days and a decrease in the number of cold nights. Projected increases in hot days frequency can exceed 10 and 40 days at the 2.1 and $4.5^{\circ} \mathrm{C}$ warming levels for southern Canada, with the largest increase in regions where hot days occur frequently in the current climate, such as in southern parts of Ontario, Quebec, and the Prairies. Even with large warming, however, temperatures in northern Canada will still be too low to have hot days. Models project a larger decrease in the number of cold nights for the north than in southern Canada, reflecting amplified high-latitude winter warming. Many regions in Canada will progressively experience unprecedented warmth. For example, hot nights (daily minimum temperature above $20{ }^{\circ} \mathrm{C}$, TN20) occur historically only in the southern part of 

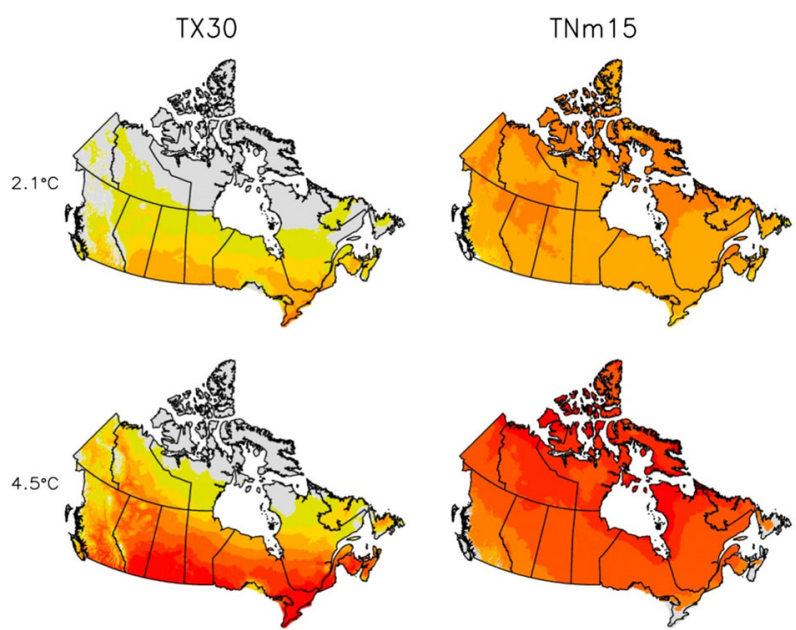

$\begin{array}{llllll}5 & 10 & 20 & 30 & 40 & 50\end{array}$

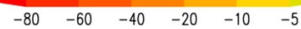

Fig. 3 Projected multi-model median changes in the number of hot days (TX30, left panel), and cold nights (TNm15, right panel) at $2.1{ }^{\circ} \mathrm{C}$ (top panel) and $4.5{ }^{\circ} \mathrm{C}$ (lower panel) global warming levels. Changes are expressed in days per year relative to the 1986 to 2005 climatology. Grid boxes are marked as gray if hot days or cold nights are not projected to occur (less than 1 day per year) in a future period

southeastern Canada. The location at which at least half of the downscaled model simulations have TN20 nights progressively expands northward with time, reaching almost $70^{\circ} \mathrm{N}$ by the end of this century under the RCP8.5 scenario (Fig. S5). Models project the disappearance of extreme cold nights (daily minimum temperature below $-25^{\circ} \mathrm{C}, \mathrm{TNm} 25$ ) by the end of this century in southern Ontario, New Brunswick, Nova Scotia, and southern Newfound and Labrador (not shown).

Models project the lengthening of the frost-free (FF) and killing-frost-free (KFF) periods, with the largest increase in British Columbia (BC) and eastern Canada and a smaller increase in the Prairies and northern territories (Fig. S6). The smaller changes in the Prairies and northern territories reflect the more pronounced annual cycle in regions with strongly continental climates, where the climatological crossing-time of the threshold occurs on the steepest part of the seasonal march of temperatures thus the change in the period above or below, a given temperature threshold is smaller. Models project an increase in the frost-free period for $\mathrm{BC}$ of up to 77 days at the $4.5^{\circ} \mathrm{C}$ global warming level; even the interior of the province, which shows the smallest increase, is projected to have an increase in frost-free period of more than 55 days.

Models also project large changes for cooling and heating degree-days, two important indices for utility planning (Fig. S7). Simulations project a substantial increase in cooling degree-days for southern Canada, especially in the most populated area of the country. A large decrease in heating degree-days is projected, especially in the north. This means that there will be stronger energy demand to meet summer cooling needs but weaker demand to meet winter warming needs. This in turn has implications for the utility sector. In fact, such a shift in the timing of energy demand has already shown its impact in Ontario's electrical energy market, there is now a summer peak, due to the recent growth in air conditioning (OPSE 2012). 
Tables S4 and S5 summarize regional averages of projected changes in climate indices at 2.1 and $4.5^{\circ} \mathrm{C}$ global warming levels. To aid interpretation, we provide a brief description of projected changes for some indices for Ontario at the $4.5^{\circ} \mathrm{C}$ global warming level (Table S5). The median projected increase in the number of hot days (TX30) is 38 annually, with the variation in projected increases between different models ranging from 15 to 56 days. Correspondingly, the number of hot spell days (TXc30) and the length of the longest hot spells (TXL30) are projected to increase by 33 and 11 days, respectively. The median projected increase in the number of hot nights (TN20), number of hot spell nights (TNc20), and length of the longest hot spell nights (TNL20) are 17, 12, and 5 nights, respectively, a pattern similar to but less pronounced than that for hot days. The projected increase in hot day and hot night frequency implies more intense, prolonged future heat waves in Ontario. Accordingly, the number of heat wave days with a daytime high temperature above $30^{\circ} \mathrm{C}$ and a nighttime low temperature above $20{ }^{\circ} \mathrm{C}$ is projected to increase by 15 days.

\subsubsection{Precipitation related indices}

Figure 4 shows multi-model median changes in the number of days with precipitation, number of days with more than $10 \mathrm{~mm}$ of precipitation (Prep10), and precipitation intensity. Overall, the models project an increase in the number of days with precipitation in the north, especially north of $60^{\circ} \mathrm{N}$, and a small decrease in parts of southern Canada. The region with an increase in the number of days with precipitation expands southward towards the end of the twenty-first century. Averaged over regions, it projected about 5 more precipitation days annually. The northern region and Quebec are exceptions, where increases of more than 15 days are projected at the $4.5{ }^{\circ} \mathrm{C}$ global warming level (Table S5). Projected changes in the annual maximum dry spell length (defined as periods of consecutive days with precipitation less than
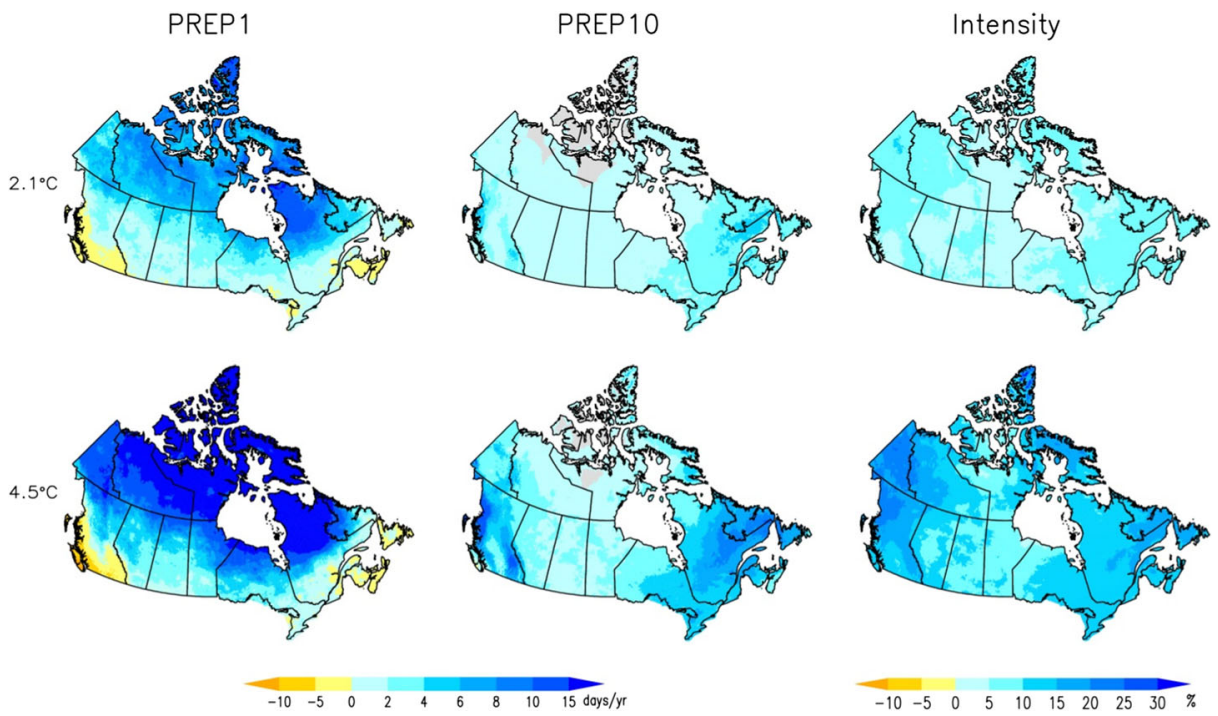

Fig. 4 Projected multi-model median changes in the number of precipitation days (PREP1, in days/year; left panel), in the number of heavy precipitation days (PREP10, in days/year; center panel), and in daily precipitation intensity (intensity, in \%; right panel) at 2.1 and $4.5^{\circ} \mathrm{C}$ global warming levels. Changes are relative to the 1986 to 2005 climatology 
$1 \mathrm{~mm}$ ) have the opposite spatial pattern (not shown), with a projected decrease in the north and small or no change in the south. Precipitation intensity is projected to increase, with a larger percentage increase of over $25 \%$ in the north at the $4.5{ }^{\circ} \mathrm{C}$ global warming level. The smallest projected percentage increases are seen in the Prairies and Nunavut, perhaps indicating differences in the ability of the atmospheric circulation to deliver moisture to the different regions of Canada. Projected changes in the number of days with precipitation over $10 \mathrm{~mm}$ have a spatial pattern similar to that of projected changes in precipitation intensity.

\subsubsection{Agroclimatic indices}

Figure 5 displays projected changes in growing season length for three main crop types at two global warming levels. As expected, the models project a lengthening in the growing season for warm season and overwintering crops as the climate warms. Climate models project an increase in the length of growing season for warm season crops in southern Canada by more than 20 days and 50 days at the 2.1 and $4.5^{\circ} \mathrm{C}$ global warming levels, respectively. In contrast, the ensemble median for the length of growing season for cool season crops decreases by up to 10 days in many regions, although not all models agree with the sign of changes. The decrease is due to earlier termination of the growing season in the summer. The accelerated physiological maturity of these crops with earlier occurrence of high temperatures (the growing season terminates on the first occurrence of daily maximum temperature greater than $30{ }^{\circ} \mathrm{C}$ for five consecutive days) is more than offsets increases from an earlier start to the growing season. Nevertheless, the length of this growing season, when averaged across regions, is projected to increase slightly (Tables S4 and S5). Models also project an increase in other heat-related
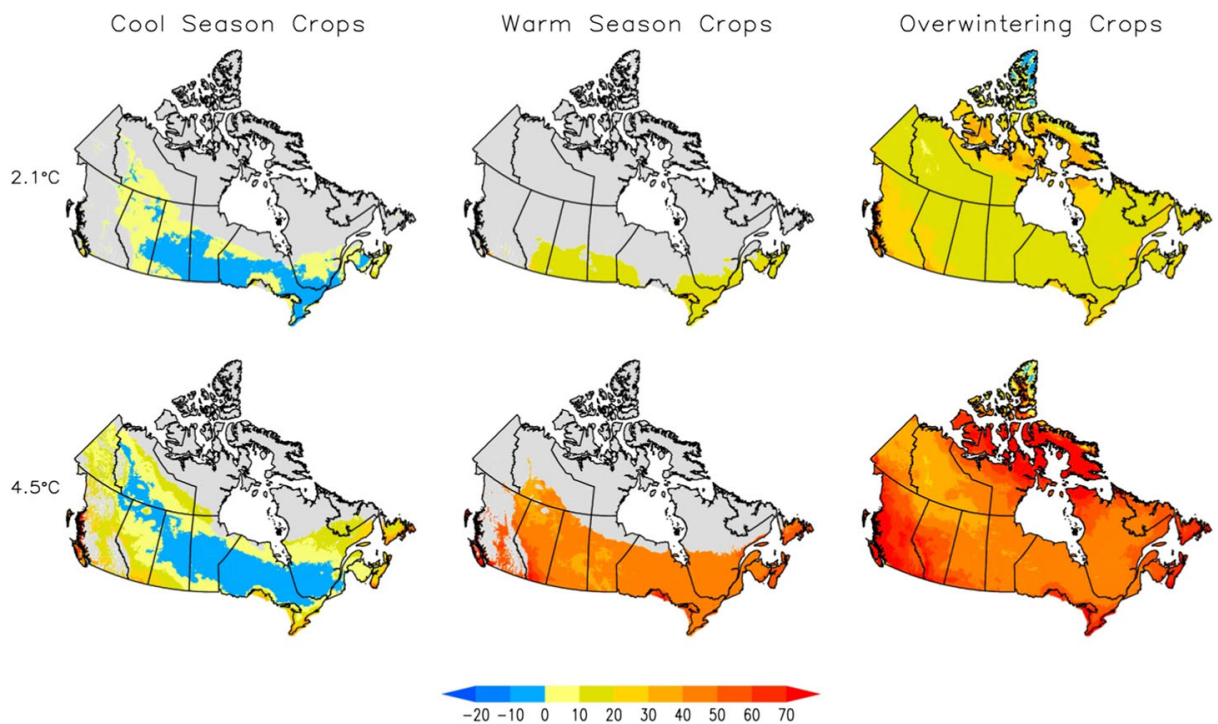

Fig. 5 Projected multi-model ensemble median changes in the length of growing seasons (in days per year) for cool season crops (left panel), warm season crops (central panel), and overwintering crops (right panel) at $2.1^{\circ} \mathrm{C}$ (upper panel) and $4.5^{\circ} \mathrm{C}$ (lower panel) global warming levels. Changes are relative to the 1986 to 2005 climatology. Grid boxes are masked gray for the cool season crops if the effective growing degree-days are projected to be less than 1200 degree-days in a future period, and for warm season crops if crop heat units are projected to be less than 2800 in a future period 
indices (not shown), including crop heat units (CHU) and effective growing degree-days (EGDD).

Spring-seeded small grain crops, such as spring wheat, require at least 1200 EGDD (Centre for Land and Biological Resources Research Branch, Agriculture and Agri-Food Canada 1995). The models project significant northward expansion of area with at least 1200 EGDD, which may reach as far north as Yukon at the $4.5{ }^{\circ} \mathrm{C}$ warming level (see Fig. 5, left). The projected warming may therefore open up new opportunities for the northward expansion of agriculture if other elements such as soil conditions and water availability are suitable and crop physiology permits. Yields for crops that can take advantage of additional heat may also improve. Qian et al. (2017) showed that global mean warming by up to $2.0{ }^{\circ} \mathrm{C}$ may be beneficial for Canadian crop production, though yield starts to decrease beyond the $2.0{ }^{\circ} \mathrm{C}$ warming level because of added water stress associated with increased evaporative demand.

\subsubsection{Uncertainty in the projections}

For temperature-related indices, projections by different models at the $2.1{ }^{\circ} \mathrm{C}$ global warming level agree on the sign of changes for almost all regions, with only a few exceptions, consistent with warming. At the $4.5^{\circ} \mathrm{C}$ global warming level, the models agree with the sign of changes for every temperature index and for every region, with only two exceptions (i.e., growing season length for cold season crops in the Prairies and Ontario). This indicates the robustness of projected changes in temperature indices for the future. In contrast, uncertainty in projected precipitation changes is large; the models do not fully agree on the sign of changes in most regions at the $2.1^{\circ} \mathrm{C}$ global warming level, but the models do agree on the sign of changes in most regions at the $4.5^{\circ} \mathrm{C}$ warming level. As summarized in Tables S4 and S5, the spread in the projected changes increases with greater global warming. To a first approximation, regional changes in the indices scale with global mean temperature change. Stronger warming in the projected global mean temperature is associated with larger uncertainty, which is largely due to model uncertainty since there is a lack of evidence for an increase in the natural internal variability with warming. It follows that the increase in the uncertainty of projected changes in the indices is also largely due to model uncertainty. Note that the perception of uncertainty may be affected by the choice of reference period (e.g., whether earlier or later in the observational record). This is because the mean anomaly is constrained to be zero during the reference period while the anomaly is not constrained in this way beyond the reference period. As a result, the spread amongst models widens as the distance in time between the base period and the projection horizon increases (see also Hawkings and Sutton 2016).

The downscaling procedure preserves observed spatial and temporal variability of precipitation and temperature at high-resolution. Preserving temperature trend is important as the models are able to simulate observed changes in Canadian temperature (Wan et al. 2018). It also removes model biases. Thus, the downscaled products are better suited for impact assessment. It should be noted however that the projected future changes by the downscaled products are not necessarily more creditable than those by the underlying climate model outputs. In many cases, especially for absolute threshold-based indices, projections based on downscaled data have smaller spread because of the removal of model biases (e.g., Fig. 1). As an example, in Ontario, the spread in projected changes in the number of days with daily maximum temperature greater than $30{ }^{\circ} \mathrm{C}$ computed from the statistically downscaled data is smaller than that computed directly from the GCMs (Fig. S8). However, this is not the case for all indices. Downscaling from GCM resolution to the fine resolution needed for impacts 
assessment increases the level of spatial detail and temporal variability to better match observations. Since these adjustments are GCM dependent, the resulting indices could have wider spread when computed from downscaled data as compared to those directly computed from GCM output. In the latter case, it is not the downscaling procedure that makes future projection more uncertain; rather, it is indicative of higher variability associated with finer spatial scale.

\section{Summary and conclusions}

We have considered a variety of impact-relevant climate indices for Canada, comparing variants of the indices computed from observations, directly from GCMs, and from statistically downscaled products. Overall, indices computed directly from GCMs are biased while those computed from downscaled GCM output agree well with observations.

We found that projected changes in Canadian temperature scale well with global mean temperature change, independent of emission scenario including RCP2.6, RCP4.5, and RCP8.5. Consequently, projected changes in the indices also scale with global mean temperature change. While expressing projected changes in indices in relation to global warming level may add some uncertainty to projections, it may help to ease communication with the impacts and adaptation community as it separates the effects of two fundamentally different types of uncertainty - modeling uncertainty and natural variability on the one hand, uncertainty in future emissions on the other. That is, it separates uncertainty that is rooted in the limitations of the scientific understanding of climate change and variability from uncertainty that is linked to social-economic development and global mitigation effort. This separation, and casting adaptation requirements relative to specified levels of warming, can be particularly useful in risk management because of difficulties in determining the most appropriate emission scenario to use for impact assessment. Overall, temperature-related indices are projected to change in step with warming, even though uncertainty exists in the magnitude of change. This includes increases in extreme high temperatures, lengthening of growing seasons for warm season and overwintering crops, and numbers of cooling degree-days and frost-free periods. Decreases are projected in heating degree-days. A noticeable exception is the modeled decrease in the growing season length for cool season crops in regions where cool season crops grow in the current climate. In this case, an earlier start to the growing season does not fully offset an earlier termination of the growing season due to warming.

Projected changes in precipitation indices indicate wetting in general, including increases in the amount and frequency of precipitation, although precipitation in small regions in the southern interior of $\mathrm{BC}$ and Atlantic Canada may decrease. However, uncertainty is large. Model agreement in the sign of changes for most of precipitation indices is poor at the $2.1{ }^{\circ} \mathrm{C}$ global warming level although model agreement becomes much better at the $4.5{ }^{\circ} \mathrm{C}$ global warming level.

It is hoped that the provision of future projections of impact-relevant climate indices will help to provide non-specialists with relatively easy access to climate information for adaptation planning. Basing the information on carefully bias-corrected and downscaled scenarios that nevertheless preserve projected changes should help to make the information more relevant to planners and decision-makers who, in almost all cases, are faced with adaptation at a local or regional scale. Projected changes in the growing season, in extreme temperatures, in indicators relevant to energy planning are large and robust even at the $2.1{ }^{\circ} \mathrm{C}$ warming level, indicating 
the need to adjust planning and practice of multiple sectors in Canada. The models project an increase in both total and extreme precipitation for the future. The high uncertainty in precipitation projections should not be a reason for ignoring the projected changes in adaptation planning. The projections do provide creditable and usable information. There is qualitative consistency between median projections under different forcing scenarios when indexed to temperature change and evidence that most indices scale with temperature changes. There is also qualitative consistency of the projected changes with the expected thermodynamically induced changes in precipitation extremes.

Acknowledgements We thank Al Douglas of Ontario Centre for Climate Impacts and Adaptation for the development of "Climate Services for Intermediate User Groups-Climate and Weather Data" from which we defined climate indices used in this paper. We thank Marjorie Shepherd and three anonymous reviewers for their constructive comments. We acknowledge the modeling groups, the Program for Climate Model Diagnosis and Intercomparison, and the WCRP's Working Group on Coupled Modeling for their roles in making available the WCRP CMIP5 multi-model dataset.

Open Access This article is distributed under the terms of the Creative Commons Attribution 4.0 International License (http://creativecommons.org/licenses/by/4.0/), which permits unrestricted use, distribution, and reproduction in any medium, provided you give appropriate credit to the original author(s) and the source, provide a link to the Creative Commons license, and indicate if changes were made.

\section{References}

Allard M, Lemay M (2012) Nunavik and Nunatsiavut: From science to policy. An Integrated Regional Impact Study (IRIS) of climate change and modernization. ArcticNet Inc., Quebec City, Canada

Beaubien EG, Hamann A (2011) Plant phenology networks of citizen scientists: recommendations from two decades of experience in Canada. Int J Biometeorol 55:833-841. https://doi.org/10.1007/s00484-011-0457-y

Bürger G, Murdock TQ, Werner AT, Sobie SR, Cannon AJ (2012) Downscaling extremes - an intercomparison of multiple statistical methods for present climate. J Clim 25:4366-4388. https://doi.org/10.1175/JCLI-D-1100408.1

Bürger G, Sobie SR, Cannon AJ, Werner AT, Murdock TQ (2013) Downscaling extremes - an intercomparison of multiple methods for future climate. J Clim 26:3429-3449. https://doi.org/10.1175/JCLI-D-12-00249.1

Cannon AJ, Sobie SR, Murdock TQ (2015) Bias correction of simulated precipitation by quantile mapping: how well do methods preserve relative changes in quantiles and extremes? J Clim 28(17):6938-6959. https://oi. org/10.1175/JCLI-D-14-00754.1

Centre for Land and Biological Resources Research Branch, Agriculture and Agri-Food Canada, (1995) Land suitability rating system for agricultural crops, spring-seeded small grains

Dixon KW, Lanzante JR, Nath MJ, Hayhoe K, Stoner A, Radhakrishnan A, Balaji V, Gaitán CF (2016) Evaluating the stationarity assumption in statistically downscaled climate projections: is past performance an indicator of future results? Clim Chang 135(3-4):395-408. https://doi. org/10.1007/s10584-016-1598-0

Ficklin DL, Abatzoglou JT, Robeson SM, Dufficy A (2016) The influence of climate model biases on projections of aridity and drought. J Clim 29:1269-1285. https://doi.org/10.1175/JCLI-D-15-0439.1

Flato G, Marotzke J, Abiodun B, Braconnot P, Chou SC, Collins W, Cox P, Driouech F, Emori S, Eyring V, Forest C, Gleckler P, Guilyardi E, Jakob C, Kattsov V, Reason C, Rummukainen M (2013) Evaluation of climate models. In: Climate change 2013: the physical science basis contribution of working group I to the fifth assessment report of the intergovernmental panel on climate change [Stocker TF, Qin F, Plattner GK, Tignor M, Allen SK, Boschung J, Nauels A, Xia Y, Bex V, Midgley PM (eds.)]. Cambridge University Press, Cambridge, United Kingdom and New York, NY, USA

Gudmundsson L, Bremnes JB, Haugen JE, Engen-Skaugen T (2012) Technical note: downscaling RCM precipitation to the station scale using statistical transformations - a comparison of methods. Hydrol Earth Syst Sci 16:3383-3390. https://doi.org/10.5194/hess-16-3383-2012

Gutmann E, Pruitt T, Clark MP, Brekke L, Arnold JR, Raff DA, Rasmussen RM (2014) An intercomparison of statistical downscaling methods used for water resource assessments in the United States. Water Resour Res. https://doi.org/10.1002/2014WR015559 
Hawkins ED, Sutton R (2016) Connecting climate model projections of global temperature change with the real world. BAMS:963-979. https://doi.org/10.1175/BAMS-D-14-00154.1

IPCC (2013) Summary for policymakers. In: Climate change 2013: the physical science basis. Contribution of working group I to the Fifth assessment report of the intergovernmental panel on climate change [Stocker TF, Qin D, Plattner GK, Tignor M, Allen SK, Boschung J, Nauels A, Xia Y, Bex V, Midgley PM (eds.)]. Cambridge University Press, Cambridge, United Kingdom and New York, NY, USA

Lobell DB, Gourdji SM (2012) The influence of climate change on global crop productivity. Plant Physiol 160: 1686-1697

Maraun D (2013) Bias correction, quantile mapping, and downscaling: revisiting the inflation issue. J Clim 26: 2137-2143. https://doi.org/10.1175/JCLI-D-12-00821.1

Maraun D (2016) Bias correcting climate change simulations - a critical review. Curr Clim Chang Rep 2(4):211220. https://doi.org/10.1007/s40641-016-0050-x

Maraun D, Shepherd TG, Widmann M, Zappa, Walton D, Gutiérrez JM, Hagemann S, Richter I, Soares PMM, Hall A, Mearns LO (2017) Towards process-informed bias correction of climate change simulations. Nat Clim Chang 7:764-773. https://doi.org/10.1038/nclimate3418

Maurer EP, Brekke L, Pruitt T, Duffy PB (2007) Fine-resolution climate projections enhance regional climate change impact studies. Eos, Trans Am Geophys Union 88(47):504-504

Maurer EP, Hidalgo HG, Das T, Dettinger MD, Cayan DR (2010) The utility of daily large-scale climate data in the assessment of climate change impacts on daily streamflow in California. Hydrol Earth Syst Sci 14:11251138. https://doi.org/10.5194/hess-14-1125-2010

McKenney DW, Hutchinson MF, Papadopol P, Lawrence K, Pedlar J, Campbell K, Milewska E, Hopk inson RF, Price D, Owen T (2011) Customized spatial climate models for North America. B Am Meteorol Soc 92: 1611-1622. https://doi.org/10.1175/2011BAMS3132.1

Mekis E, Vincent LA (2011) An overview of the second generation adjusted daily precipitation dataset for trend analysis in Canada. Atmosphere - Ocean 49(2). https://doi.org/10.1080/07055900.2011.583910

Murdock TQ, Cannon AJ, Sobie SR (2014) Statistical downscaling of future climate projections for North America. Pacific Climate Impacts Consortium report on Contract No. KM040-131148/A. Prepared for Environment Canada. March 2014. Victoria, Canada. 37 pp. (https://www.pacificclimate. org/sites/default/files/publications/PCIC_EC_downscaling_report_2014.pdf)

OPSE (Ontario Society of Professional Engineers) (2012) Wind and the electrical grid mitigating the rise in electricity rates and greenhouse gas emissions, https://www.ospe.on.ca/public/documents/advocacy/2012wind-electrical-grid.pdf Accessed 16 August 2016

Prowse TD, Furgal C, Chouinard R, Melling H, Milburn D, Smith SL (2009) Implications of climate change for economic development in northern Canada: energy, resource, and transportation sectors. Ambio 38:272281. https://doi.org/10.1579/0044-7447-38.5.272

Qian B, Gameda S, Zhang X, De Jong R (2012) Changing growing season observed in Canada. Clim Chang 112: 339-353

Qian B, De Jong R, Gameda S, Huffman T, Neilsen D, Desjardins R, Wang H, McConkey B (2013) Impact of climate change scenarios on Canadian agroclimatic indices. Can J Soil Sci 93:243-259

Qian B, Zhang X, Smith W, Grant B, Jing Q, Cannon A, Neilsen D, McConkey B, Li G, Bonsal B, Wan H and Xue L (2017) Climate impacts on Canadian yields of spring wheat, canola and maize for global warming levels of $1.5,2.0$ and $2.5^{\circ} \mathrm{C}$. Environ Res Lett, submitted

Qian B, Jing Q, Bélanger G, Shang J, Huffman T, Liu J, Hoogenboom G (2018) Simulated canola yield responses to climate change and adaptation in Canada. Agron J 110:1-14. https://doi.org/10.2134 /agronj2017.02.0076

Sillmann J, Kharin VV, Zwiers FW, Zhang X (2013a) Climate extreme indices in the CMIP5 multi-model ensemble, part 1: model evaluation in the present climate, doi: https://doi.org/10.1002/jgrd.50203

Sillmann J, Kharin VV, Zwiers FW, Zhang X (2013b) Climate extreme indices in the CMIP5 multi-model ensemble, part 2: future climate projections. JGR-Atmosphere. https://doi.org/10.1002/jgrd.50188

Seneviratne SI, Donat MG, Pitman AJ, Knutti R, Wilby RL (2016) Allowable CO2 emissions based on regional and impact-related climate targets. Nature 529:477-483. https://doi.org/10.1038/nature16542

Stephani E, Fortier D, Shur Y, Fortier R, Doré G (2014) A geosystems approach to permafrost investigations for engineering applications, an example from a road stabilization experiment, Beaver Creek, Yukon, Canada. Cold Reg Sci Technol 100:20-35. https://doi.org/10.1016/j.coldregions.2013.12.006

Thrasher B, Maurer EP, McKellar C, Duffy PB (2012) Technical note: bias correcting climate model simulated daily temperature extremes with quantile mapping. Hydrol Earth Syst Sci 16:3309-3314. https://doi. org/10.5194/hess-16-3309-2012

van Vuuren DP, Edmonds J, Kainuma M, Riahi K, Thomson A, Hibbard K, Hurtt GC, Kram T, Krey V, Lamarque JF, Masui T, Meinshausen M, Nakicenovic N, Smith SJ, Rose SK (2011) The representative concentration pathways: an overview. Clim Chang 109:5-31. https://doi.org/10.1007/s10584-011-0148-Z 
Vincent LA, Wang XL, Milewska EJ, Wan H, Yang F, Swail V (2012) A second generation of homogenized Canadian monthly surface air temperature for climate trend analysis, J Geophys Res Atmos 117,17: doi: https://doi.org/10.1029/2012JD017859

Wan H, Zhang X, Zwiers FW (2018) Human influence on Canadian temperatures. Clim Dyn. https://doi. org/10.1007/s00382-018-4145-Z

Warren FJ, Lemmen DS (2014) Synthesis - Canada in a changing climate: sector perspectives on impacts and adaptation, Government of Canada, Ottawa, ON, pp1-18

Werner AT, Cannon AJ (2016) Hydrologic extremes - an intercomparison of multiple gridded statistical downscaling methods. Hydrol Earth Sys Sci 20:1483-1508. https://doi.org/10.5194/hess-20-1483-2016

Wilbanks TJ, Bhatt V, Bilello DE, Bull SR, Ekmann J, Horak WC, Huang YJ, Levine MD, Sale MJ, Schmalzer DK, Scott MJ (2008) Effects of climate change on energy production and use in the United States. U.S. Climate Change Science Program Synthesis and Assessment Product 4.5

Wood AW, Leung LR, Sridhar V, Lettenmaier DP (2004) Hydrologic implications of dynamical and statistical approaches to downscaling climate model outputs. Clim Chang 62:189-216

Zhang X, Alexander L, Hegerl GC, Jones P, Tank AK, Peterson TC, Trewin B, Zwiers FW (2011) Indices for monitoring changes in extremes based on daily temperature and precipitation data. WIREs Clim Change. https://doi.org/10.1002/wcc.147 